\title{
Current situation and influencing factors of the nursing practice environment in five tertiary general hospitals in Shenzhen: a cross-sectional study
}

\author{
Wenjuan Lai ${ }^{1} \cdot$ Rongxiu Jin ${ }^{1} \cdot$ Ruoying $\mathrm{He}^{1} \cdot$ Xiaorong Ding ${ }^{1}$ \\ Received: 31 August 2020 / Accepted: 13 February 2021 / Published online: 5 March 2021 \\ (C) The Author(s), under exclusive licence to Springer-Verlag GmbH Germany, part of Springer Nature 2021
}

\begin{abstract}
Objective This study investigates the current situation and influencing factors of the nursing practice environment in Shenzhen, China, and provides suggestions for improving it.

Background Nursing shortage is an urgent global problem and also of concern in China. Studies have shown that better work environments are related to high job satisfaction and better patient outcomes.

Methods The 37-item Practice Environment Scale was used to assess the nursing practice environment. Respondents were 1116 nurses from five general tertiary hospitals in Shenzhen.

Results The mean satisfaction score for the nursing practice environment was $3.63 \pm 0.72$ (where 5 is the highest possible score). Position, being a specialist nurse, choice of nursing major, educational attainment, and night shifts significantly affected nurses' working environment satisfaction.

Conclusion The practice environment of nurses was satisfactory. We recommend reducing the workload and encouraging nurses to complete specialist training, and supporting nurses to expand their roles in hospitals and society to improve the nursing practice environment.
\end{abstract}

Keywords Nursing practice environment · Job satisfaction · Treatment effect · A cross-sectional study

\section{Introduction}

The global health care system is undergoing significant changes, particularly in the management of a shortage of medical resources. Nursing resources are in short supply in many countries. Simultaneously, the demand related to the needs of patients with acute and chronic diseases is increasing (Goh et al. 2015). Studies have shown that the general shortage of nursing resources may exacerbate nurses' dissatisfaction with their working environment. Some international studies (Kang et al. 2014a, b; Wang et al. 2015) indicate that improving nurses' job satisfaction may be a way to solve the nursing shortage (Kash et al. 2010). Djukic's research found that, in addition to staffing, working environment factors are

\section{Xiaorong Ding}

1 Nursing Department, Peking University Shenzhen Hospital, 1120 Lianhua Road, Futian District, Guangdong 518036 Shenzhen, China related to nurses' evaluation of patient care quality (Djukic et al., 2013). The nursing work environment may be defined as: an organizational feature of the work environment that helps or restricts professional nursing practice (Lake et al. 2002). The nursing work environment is a multi-factor structure composed of five characteristics: (1) nurses' involvement in hospital affairs, (2) the basis of nursing quality, (3) the ability, leadership, and support of nurse managers, (4) adequate staffing and resources, and (5) the relationship between doctors and nurses.

It has been proved that the nursing work environment is related to adverse events for patients in the hospital. The incidence of patient falls in hospitals that provide excellent good care practices are $5 \%$ lower than in hospitals that do not provide this method (Bae 2011). A good nursing practice environment can not only reduce patients' adverse events (such as hospital infections and medication errors), but also improve the overall quality of care (Grant 2009). Research by Stalpers et al. found other characteristics of nurse staffing and work environment (for example, partnership, experience, and education). The 
nursing practice environment has a significant impact on falls, pain management, and pressure ulcers. Therefore, a more favorable working environment can help improve the prognosis of patients (Stalpers et al. 2015).

Aiken et al. conducted a cross-sectional survey in 12 countries/regions, mainly investigating the quality of nurse staffing and hospital working environment (management support for nursing, good medical-care relationship, nurses' participation in decision-making, and organizational priorities). These factors are significantly related to patient satisfaction, care quality and safety, and nurses' work results (Aiken, 2012). Therefore, creating a pleasant nursing practice environment is of considerable significance to improving medical care quality. This study aims to explore the current status of the nursing practice environment in a general tertiary hospital in Shenzhen, China, to discuss the possible influencing factors of the hospital nursing practice environment, and to put forward suggestions for improvement.

\section{Methods}

\section{Respondents}

Convenience sampling was used to select five AAA-grade hospitals (i.e., highest rated hospitals based on the Chinese hospital classification) in Shenzhen, China. Registered nurses from these hospitals completed a questionnaire on their practice environment. Participation in this survey was voluntary and anonymous through the use of an electronic link. Inclusion criteria were as follows: (1) working in the hospital for 1 year or longer; (2) working as a clinical nurse or in a position related to nursing management; (3) having volunteered to participate and provided informed consent. Nurses with a diagnosis of psychological or cognitive disturbances in the past and/or at present were excluded.

\section{Questionnaire}

The study questionnaire was completed online. Nurses' basic characteristics were collected, such as gender, age, marital status, educational background (i.e., first academic degree or/and highest educational attainment), years in nursing, nursing professional title, number of night shifts, and position. Moreover, the Practice Environment Scale of the Nursing Work Index was designed based on three previous studies (Lake et al. 2002; Wang and Li 2011; Ying et al. 2016), and was used to measure nurses' satisfaction with practice environment. This scale comprises 37 items, and respondents rate the extent to which they are satisfied with each item on a 5 -point Likert scale $(1=$ very dissatisfied, $2=$ dissatisfied, $3=$ neutral, $4=$ satisfied, and $5=$ very satis fied), with higher scores indicating more favorable nursing practice environments. Following two rounds of "Discussion-Preliminary Survey-Revision," the final Cronbach's alpha was 0.981 , and KMO was 0.980 , indicating high construct validity.

\section{Data collection}

The study protocol was approved by the Peking University Shenzhen Hospital Ethics Committee. Participating nurses were informed of the purpose of the study and how the study results would be used to create a more supportive practice environment. The web-based survey included completion instructions and an explanation of the study aims. The survey results were directly uploaded to the researcher. It was planned that the percentage of participating nurses, regardless of their department, should account for $30 \%$ of all nurses working in each of the five hospitals. The survey was thus distributed to 1116 nurses, and 1116 questionnaires were returned, yielding a response rate of $100 \%$.

\section{Statistical analysis}

Data analysis was carried out using SPSS 21.0. T-test or analysis of variance were used to compare scores of nursing practice environment according to the different variables. Oneway ANOVA and multiple linear regression analysis were used to analyze relevant influencing factors. A $p$ value of less than 0.05 was considered statistically significant.

\section{Results}

\section{Participant characteristics}

A total of 1116 nurses returned the questionnaire from the five hospitals. The characteristics of these nurses are presented in Table 1. The average age was $30.59 \pm 6.47$ years, and the average number of years working in nursing was $9.37 \pm 7.2$. There were 96 males and 1020 females, accounting for $8.6 \%$ and $91.4 \%$ of the sample respectively.

\section{Scores of nursing practice environment}

The overall datisfaction score for the nursing practice environment was $3.63 \pm 0.72$. Table 2 shows the scale items ranked in descending score order.

\section{Factors influencing nursing practice environment}

The regression analysis included the nursing practice environment score as the dependent variable, and the independent variables were those showing significant associations in 
Table 1 Participant

characteristics and scores of nursing practice environment with corresponding differences

\begin{tabular}{|c|c|c|c|c|c|}
\hline Independent variable & Group & Number & Percentage & $\begin{array}{l}\text { Mean } \pm \text { standard } \\
\text { deviation }\end{array}$ & $\begin{array}{l}P \\
\text { value }\end{array}$ \\
\hline \multirow[t]{2}{*}{ Gender } & Male & 96 & 8.60 & $3.56 \pm 0.86$ & \multirow[t]{2}{*}{0.354} \\
\hline & Female & 1020 & 91.40 & $3.63 \pm 0.71$ & \\
\hline \multirow[t]{3}{*}{ Position } & Bedside nurse & 1039 & 93.10 & $3.60 \pm 0.73$ & \multirow[t]{3}{*}{0.001} \\
\hline & Group leader nurse & 74 & 6.60 & $3.97 \pm 0.56$ & \\
\hline & Head nurse & 3 & 0.30 & $4.05 \pm 0.87$ & \\
\hline \multirow[t]{2}{*}{ Specialist nurse } & Yes & 296 & 26.50 & $3.72 \pm 0.76$ & \multirow[t]{2}{*}{0.01} \\
\hline & No & 820 & 73.50 & $3.59 \pm 0.71$ & \\
\hline \multirow[t]{4}{*}{ Professional title } & Nurse & 754 & 67.60 & $3.65 \pm 0.72$ & \multirow[t]{4}{*}{0.00} \\
\hline & Nurse-in-charge & 299 & 26.80 & $3.52 \pm 0.75$ & \\
\hline & $\begin{array}{l}\text { Associate professor of } \\
\text { nursing }\end{array}$ & 53 & 4.70 & $3.81 \pm 0.64$ & \\
\hline & Professor of nursing & 10 & 0.90 & $3.96 \pm 0.62$ & \\
\hline \multirow{2}{*}{$\begin{array}{l}\text { Choice of nursing } \\
\text { major }\end{array}$} & Nursing as first choice & 950 & 85.10 & $3.66 \pm 0.72$ & \multirow[t]{2}{*}{0.002} \\
\hline & $\begin{array}{l}\text { Required substantial } \\
\text { adjustment to nursing }\end{array}$ & 166 & 14.90 & $3.47 \pm 0.75$ & \\
\hline \multirow[t]{4}{*}{ First academic degree } & $\begin{array}{l}\text { Secondary technical } \\
\text { certificate }\end{array}$ & 422 & 37.80 & $3.64 \pm 0.67$ & \multirow[t]{4}{*}{0.55} \\
\hline & Associate degree & 510 & 45.70 & $3.60 \pm 0.78$ & \\
\hline & Bachelor's degree & 182 & 16.30 & $3.68 \pm 0.69$ & \\
\hline & Master's degree & 2 & 0.20 & $3.48 \pm 0.47$ & \\
\hline \multirow[t]{4}{*}{$\begin{array}{l}\text { Highest educational } \\
\text { attainment }\end{array}$} & $\begin{array}{l}\text { Secondary technical } \\
\text { certificate }\end{array}$ & 13 & 1.20 & $3.89 \pm 0.87$ & \multirow[t]{4}{*}{0.028} \\
\hline & Associate degree & 268 & 24.00 & $3.71 \pm 0.75$ & \\
\hline & Bachelor's degree & 827 & 74.10 & $3.59 \pm 0.71$ & \\
\hline & Master's degree & 8 & 0.70 & $3.94 \pm 0.46$ & \\
\hline \multirow[t]{3}{*}{ Marital status } & Married & 664 & 59.50 & $3.61 \pm 0.70$ & \multirow[t]{3}{*}{0.208} \\
\hline & Single & 432 & 38.70 & $3.66 \pm 0.74$ & \\
\hline & Divorced & 20 & 1.80 & $3.42 \pm 1.01$ & \\
\hline \multirow{5}{*}{$\begin{array}{l}\text { Monthly average of } \\
\text { night shifts }\end{array}$} & $0-5$ & 550 & 49.30 & $3.69 \pm 0.73$ & \multirow[t]{5}{*}{0.004} \\
\hline & $6-10$ & 431 & 38.60 & $3.60 \pm 0.72$ & \\
\hline & $11-15$ & 93 & 8.30 & $3.41 \pm 0.70$ & \\
\hline & $16-20$ & 10 & 0.90 & $3.73 \pm 0.51$ & \\
\hline & $21-25$ & 32 & 2.90 & $3.49 \pm 0.60$ & \\
\hline \multirow[t]{2}{*}{ Contract type } & Temporary employee & 749 & 67.10 & $3.59 \pm 0.72$ & \multirow[t]{2}{*}{0.028} \\
\hline & Permanent staff & 323 & 28.90 & $3.64 \pm 0.69$ & \\
\hline \multirow{2}{*}{$\begin{array}{l}\text { Household } \\
\text { registration }\end{array}$} & Guangdong Province & 792 & 71.00 & $3.60 \pm 0.71$ & \multirow[t]{2}{*}{0.107} \\
\hline & Non-Guangdong Province & 324 & 29.00 & $3.68 \pm 0.77$ & \\
\hline \multirow[t]{2}{*}{ Hospital category } & Comprehensive & 291 & 26.10 & $3.63 \pm 0.69$ & \multirow[t]{2}{*}{0.878} \\
\hline & Specialized & 825 & 73.90 & $3.63 \pm 0.74$ & \\
\hline
\end{tabular}

univariate analyses: position, being a specialist nurse, professional title, choice of nursing major, highest educational attainment, monthly average of night shifts, and contract type (see Table 1). The results of the regression analysis are shown in Table 3. Table 4 shows that position, being a specialist nurse, choice of nursing major, highest educational attainment, and monthly average of night shifts were significant factors influencing nurses' satisfaction with their practice environment.

\section{Discussion}

\section{Nursing practice environment in Shenzhen}

The "New Nurses Standardization Training Program" and "National Nursing Development Program (2016-2020)" were issued by the China Health and Family Planning Commission in 2016. This policy development can undoubtedly improve nursing services and improve the quality of care. This is an 
Table 2 Items of nursing practice environment listed in descending order of mean score
Items

Mean \pm standard deviation

23. Systematic training is provided to newly recruited nurses

$4.06 \pm 0.73$

20. There is an established post-exposure occupational management system that can be carried out effectively

24. Corresponding continuing education is provided to nurses relevant to their job requirements

28. Nurses in the work team are competent in their jobs

$4.01 \pm 0.78$

$3.93 \pm 0.80$

$3.93 \pm 0.76$

10. There are clear guidelines on roles and responsibilities of nurses

$3.91 \pm 0.85$

11. There is a well-functioning nursing working system

$3.91 \pm 0.84$

15. The nursing team often discusses patient care and seeks improvement

$3.91 \pm 0.82$

12. There is a work process with clear guidance that is easy to implement

$3.89 \pm 0.82$

4. Nurses are able to assess patients and deliver individual nursing care based on the assessment results

31. Usually there are no frequent job changes among nursing backbones

$3.88 \pm 0.84$

$3.88 \pm 0.79$

22. Medical staff including doctors and nurses can perform their own job adequately and work together to coordinate their jobs

13. The hospital management department expects each nursing unit to deliver high-quality patient care

5. The clinical work in the hospital reflects and demonstrates the characteristics of professional nursing care

21. There is a harmonious relationship between doctors and nurses in the department $\quad 3.84 \pm 0.85$

6. The nursing administrator often discusses daily nursing work with bedside nurses and $\quad 3.80 \pm 0.91$ listens to their opinions

30. The nursing shift scheduling adequately matches nurses with varied competency levels

8. The nursing administrator agrees with sensible decisions made by bedside nurses

$3.80 \pm 0.89$

$3.73 \pm 0.91$

7. Nurses with good job performance are encouraged and recognized in a timely manner

$3.72 \pm 0.94$

14. The nursing shift scheduling is conducive to continuing nursing care of patients

$3.72 \pm 0.91$

19. Occupational prevention and protection is available at work for nurses

$3.69 \pm 0.95$

9. When nurses make mistakes in their job, the nursing administrator provides them with conductive advice instead of blindly criticizing them.

26. There is a clear career path or professional promotion system for nurses in the hospital

25. Nurses have the opportunity to attend academic activities domestically and abroad

18. Hospital is well equipped to improve the efficiency of nursing work

$3.68 \pm 0.98$

$3.68 \pm 0.91$

$3.67 \pm 0.92$

$3.56 \pm 0.96$

37. Your overall assessment of the nurse practitioner's practice environment in your

$3.54 \pm 0.95$ hospital

17. The hospital administrative department is supportive of clinical nursing work

$3.46 \pm 0.99$

$3.46 \pm 1.08$

$3.46 \pm 0.97$

33. A feeling of trust and respect from patients can be sensed by nurses at work

$3.45 \pm 1.05$

16. The clinical support system allows nurses more time to provide care for patients

$3.31 \pm 1.10$

29. The current working hours and labor intensity are well matched

$3.31 \pm 1.13$

36. Nurses are able to enjoy statutory
overtime allowance, insurance, etc.

32. The work of nurses is appreciated and recognized by the public $\quad 3.30 \pm 1.09$

1. Nurses can participate in hospital internal management

$3.23 \pm 1.03$

3. Nurses have the opportunity to become members of the hospital management committee

35. The salary of nurses is just as good as that in other professions

$3.15 \pm 1.08$

$2.96 \pm 1.14$

$2.95 \pm 1.15$

$2.87 \pm 1.11$ important measure to deepen medical reform and benefit the people, and is an important part of the "Action Plan to Further Improve Medical Services." This study shows that nursing staff in Shenzhen are generally satisfied with their practice environment, with an average total score of $3.63 \pm 0.72$, and the average score of most items is above 3 . This reflects the 
Table 3 Analysis of variance of regression model

\begin{tabular}{lcrllll}
\hline & Sum of squares & df & & Mean squares & F & $P$ value \\
\hline Regression & 32.565 & 7.00 & 4.65 & 9.341 & 0.000 \\
Residuals & 551.84 & 1108.00 & 0.50 & & \\
Total & 584.404 & 1115.00 & & & \\
\hline
\end{tabular}

importance of developing appropriate work policies and procedures for nursing staff. The improvement of the hospital management system and the rapid development of nursing disciplines may have affected this result. And more and more attention is paid to the establishment of nursing-related systems and processes (Lee et al. 2014; Choi et al. 2013).

On the other hand, the projects with the lowest scores indicate that the reform of the modern hospital management system is still the main challenge faced by municipal AAA hospitals. Issues such as the implementation of unit management and transactional leadership style need further improvement (Liu et al. 2012). In addition, "the hospital salary system is reasonable" and "the salary of nurses is just as good as that in other professions" also scored lower. Studies have shown that factors such as large workload and insufficient understanding of labor value greatly reduce nurses' enthusiasm, initiative, professionalism, and sense of responsibility. This also affects the stability of nursing staff, leads to an increase in staff turnover, and affects the quality of care (Choi et al. 2011). In addition, Shenzhen is an economically developed city, with a fast pace of life and work, and a high level of consumption. The citizens are under tremendous work pressure and fierce market competition. These unique regional and economic characteristics of Shenzhen may exacerbate nurses' dissatisfaction with their salary.

\section{Factors influencing nursing practice environment}

\section{Nursing position}

The study found a significant association between nurses' position and practice environment, with nurses in higher positions showing higher satisfaction with their practice environment. It has been reported that nurses receiving a promotion are more motivated to work harder and have higher selfefficacy and stronger professional identity. Furthermore, nurses in higher positions have better management ability, enjoy more chances to complete further nursing training, and can participate in decision-making concerning hospital internal affairs (Kash et al. 2010).

\section{Nursing major as first choice and being a specialist nurse}

The study shows that specialist nurses are highly satisfied with their practice environment. This indicates that specialist nurses may be more enthusiastic about nursing, treat nursing as a meaningful job, and achieve self-worth in helping patients. Also, there are significant differences between specialist nurses and non-specialist nurses in terms of satisfaction with their nursing practice environment. Specialist nurses are more satisfied with the practice environment, which shows differences between the practice environments of these groups. As nursing has become a discipline in China, the importance of professional skills has become increasingly significant to nurses, and their number is increasing. Specialist nurses have a solid professional foundation in nursing knowledge and skills. There is no doubt that this plays an important role in non-specialist nurses' clinical practice skills, promoting advancement in the field of nursing, and promoting public health. This can improve the satisfaction of their nursing environment (Doran et al. 2014).

\section{Highest educational attainment and monthly night shifts}

Research shows that people with higher education are less satisfied with the nursing practice environment. The nursing profession is highly practical, and the continuous pursuit of higher education does not match clinical practice. Nurses with different educational backgrounds all face the same job when entering clinical practice. As a result, people with high education lose motivation, and there is a tremendous psychological

Table 4 Linear regression model of overall scores of nurse practicing environment

\begin{tabular}{llllr}
\hline Variable & Regression coefficient & Standard error & Standard regression coefficient & $\mathrm{t}$ \\
\hline (Constant) & 4.098 & 0.18 & 22.542 & 0.000 \\
4. Position & 0.545 & 0.10 & 0.20 & 5.713 \\
5. Specialist nurse & 0.097 & 0.05 & $0.000^{*}$ \\
6. Professional title & -0.087 & 0.05 & -0.06 & $0.043^{*}$ \\
7. Choice of nursing major (first choice) & 0.178 & 0.06 & -0.08 & -1.822 \\
9. Highest educational attainment & -0.094 & 0.05 & -0.09 & 2.988 \\
14. Monthly average of night shifts & -0.087 & 0.02 & $0.003: *$ \\
15. Contract type & -0.069 & 0.05 & -0.11 & -2.032 \\
\hline
\end{tabular}

$*=$ statistically significant 
imbalance between them. This study also showed that the average number of night shifts per month affects satisfaction with the nursing practice environment. Nurses with fewer night shifts are more satisfied with their working environment. Studies have shown that nursing workload and time allocation are the two primary sources of nurses' work stress (Munyewende et al. 2014). Because night shifts mean longer working hours, reversed biological clocks, and excessive workload, irregular work is related to lack of rest and tension, making nurses more likely to feel stressed and dissatisfied with their working environment (Rivaz et al. 2017).

\section{Coronavirus outbreak}

Compared with the SARS epidemic, new coronary pneumonia is more infectious, spreads more widely, and has a relatively low mortality rate ( $\mathrm{Li}$ et al. 2020). The lockdown and isolation caused by the sudden major epidemic affect people's lives and severely impact people's psychology, and anxiety and panic can follow. Nurses undertake a large amount of nursing work due to the close contact and the lack of timely supply of tight protective equipment (Huang et al. 2020). Therefore, nurses are under tremendous physical and psychological pressure and have the risk of infection. This undoubtedly affects the nursing practice environment.

\section{Measures to improve nursing practice environment}

\section{Renew management concept}

Managers at all levels should take the initiative in creating a favorable nursing practice environment by establishing an effective system to create various types of working groups/committees, with nurses becoming one of them (Clavelle et al. 2013). They should encourage and guide nurses in the management of hospital affairs and open channels of communication with them. Updating the management concept and applying the theories of "authorization" and "empowerment" could increase the value of management by developing a closedloop management system through education, practice, job competency evaluation, qualification certification, and authorization (Grant et al. 2010). At the same time, transforming management from vertical to flat and flexible management, which is people-oriented, can improve work efficiency. This could not only enhance the sense of self-efficacy and responsibility of nurses, but also effectively reduce the occurrence of adverse nursing events and improve patients' well-being (Van Bogaert et al. 2012).

\section{Training and deployment of specialist nurses}

Specialist nurses play an essential role in shortening patients' hospital stay, reducing the incidence of complications, decreasing medical costs, and improving patients' life quality. Simultaneously, specialist nurses' roles and functions enhance the professional status of nurses, facilitate cooperation with physicians, and improve medical care quality. Managers should train specialist nurses in more fields, which is of considerable significance to promote specialist nursing development. It is also crucial to improve the management system of specialist nurses and train them in a planned and stratified way to stimulate the vitality of the specialist nursing team and increase their job satisfaction and sense of value.

\section{Reform of nursing scheduling model}

Variations of the shift scheduling model are running in most hospitals in Shenzhen. A study conducted by hospital managers comparing different nursing scheduling models is strongly focused on identifying the best models, finding a reasonable frequency of night shifts, and reducing night shift nurses' workload. This may help nurses to develop a more positive and optimistic attitude toward night shifts.

\section{Use of intelligent nursing equipment}

One of the factors contributing to nurse shortage in Shenzhen is a large population. We should make full use of Shenzhen's high-tech advantages, apply information and intelligent technology to nursing work, and reduce low-tech, repetitive, and indirect nursing workload (Yang et al. 2017). For example, artificial intelligence-assisted decision-making helps nurses find the best interventions for patients with reduced manual intervention. Simple, repetitive, and low-skilled tasks can be handed over to intelligent robots. This can remedy the situation of serious shortage of human resources for nursing, relieve the stress of doctors and patients, improve the relationship between nurses and patients, and continuously optimize the quality of care services to ensure the occupational safety of nurses. It is of great significance to reduce occupational exposure rate, reduce burnout, and improve nurses' practice environment and satisfaction.

\section{Strengthen training and education of infectious diseases and strengthen protection}

Strengthening the awareness of and education regarding this large-scale infectious disease are important. If the source of infection is well managed, the transmission route is cut off, and disinfection and isolation and scientific protection are done, COVID-19 is not terrible (Fathizadeh et al. 2020). In addition, it is important to strengthen the skill training and quality training of young nurses, make them proficient in various working procedures and protective skills, form a reasonable emergency echelon, prepare without chaos, and better respond to public medical emergencies, and also to Improve 
the concept of epidemic prevention of medical staff, strengthen crisis awareness, and do a good job of self-protection. Standardized nursing operations should be put in place to avoid cross-infection as much as possible (Yao et al. 2020). Furher actions should be put in place to ensure the quality of protective equipment and improve disinfection and isolation measures, strengthen air disinfection and circulation, reduce the chance of cross-infection of patients, be vigilant in restrooms or dining places to avoid cross-infection of medical staff, and establish a vertical joint care model to reduce the chance of cross-infection.

Improving the nursing practice environment should be based on a joint effort of medical institutions, nursing managers, and nurses. Updating the management concept and establishing a long-term system to encourage nurses to participate in the management of hospital and departments could increase their professional value, create a beneficial practicing environment, and improve the quality of patient care.

Authors' contributions Ding X. and Lai W. are the guarantors of integrity of the entire study, Ding X. and Lai W. designed the study and defined the intellectual content. Jin R. and Lai W. acquired the data and analyzed the data. Lai W. and He R. prepared the paper and editted the paper. All authors have read the final paper and approved.

Availability of data and material The datasets used during the present study are available from the corresponding author upon reasonable request.

Code availability Not applicable.

\section{Declaration}

Ethics approval The present study protocol was approved by the Peking University Shenzhen Hospital Ethics Committee.

Consent to participate Participating nurses were informed of the purpose of the study, and how the study results would be used to create a more supportive practice environment.

Consent for publication Not applicable.

Conflict of interest There are no conflicts of interest.

\section{References}

Aiken LH (2012) Patient safety, satisfaction, and quality of hospital care: cross sectional surveys of nurses and patients in 12 countries in europe and the united states. BMJ 344:e1717. https://doi.org/10. 1136/bmj.e1717

Bae SH (2011) Assessing the relationships between nurse working conditions and patient outcomes: systematic literature review. J Nurs Manag 19(6):700-713. https://doi.org/10.1111/j.1365-2834.2011. 01291.x

Bogaert PV, Clarke S, Willems R, Mondelaers M et al (2012) Nurse practice environment, workload, burnout, job outcomes, and quality of care in psychiatric hospitals: a structural equation model approach. J Adv Nurs 69(7):1515-1524. https://doi.org/10.1111/jan. 12010

Choi PP, Pang MC, Cheung K, Wong TKS. Choi PP, Pang MC, Cheung $\mathrm{K}$, Wong KS et al (2011) Stabilizing and destabilizing forces in the nursing work environment: a qualitative study on turnover intention. Int J Nurs Stud 48(10):1290-1301. https://doi.org/10.1016/j. ijnurstu.2011.03.005

Choi SPP, Cheung KIN, Pang SMC, Choi PP, Cheung K, Pang MC et al (2013) Attributes of nursing work environment as predictors of registered nurses' job satisfaction and intention to leave. J Nurs Manag 21(3):429-439. https://doi.org/10.1111/j.1365-2834.2012.01415.x

Clavelle JT, Porter O'Grady T, Drenkard K (2013) Structural empowerment and the nursing practice environment in magnet organizations. J Nurs Adm 43(11):566. https://doi.org/10.1097/01.NNA. $0000434512.81997 .3 \mathrm{f}$

Djukic M, Kovner CT, Brewer CS, Fatehi FK, Cline DD et al (2013) Work environment factors other than staffing associated with nurses' ratings of patient care quality. J Nurs Adm 38(2):105-114. https:// doi.org/10.1097/HMR.0b013e3182388cc3

Doran D, Duffield C, Rizk P, Nahm S, Chu CH et al (2014) A descriptive study of employment patterns and work environment outcomes of specialist nurses in Canada. Clin Nurse Spec 28(2):105-114. https:// doi.org/10.1097/NUR.0000000000000031

Fathizadeh H, Maroufi P, Momen-Heravi M, Dao S, Kose S et al (2020) Protection and disinfection policies against SARS-CoV-2 (COVID19). Infez Med 28(2):185-191

Goh YS, Lee A, Chan WC, Chan MF et al (2015) Profiling nurses' job satisfaction, acculturation, work environment, stress, cultural values and coping abilities: a cluster analysis. Int J Nurs Pract 21(4), 443. https://doi.org/10.1111/ijn.12318

Grant D (2009) Physician financial incentives and cesarean delivery: new conclusions from the healthcare cost and utilization project. J Health Econ 28(1):244-250. https://doi.org/10.1016/j.jhealeco.2008.09. 005

Grant B, Colello S, Riehle M, Dende D et al (2010) An evaluation of the nursing practice environment and successful change management using the new generation magnet model. J Nurs Manag 18(3): 326-331. https://doi.org/10.1111/j.1365-2834.2010.01076.x

Huang X, Wang L, Dong X, Li B, Wan Q et al (2020) Effects of nursing work environment on work-related outcomes among psychiatric nurses: a mediating model. J Psychiatr Ment Health Nurs 2020 June (online ahead of print). https://doi.org/10.1111/jpm.12665

Kang JH, Kim CW, Lee SY et al (2014a) Nurse-perceived patient adverse events and nursing practice environment. J Prev Med Public Health 47(5):273-280. https://doi.org/10.3961/jpmph.14.019

Kang JC, Kim SL, Kang JH, Kim CW, Lee SY et al (2014b) Nurseperceived patient adverse events and nursing practice environment. J Prev Med Public Health 47(5):273-280. https://doi.org/10.3961/ jpmph.14.019

Kash BA, Naufal GS, Dagher RK, Johnson CE et al (2010) Individual factors associated with intentions to leave among directors of nursing in nursing homes. Health Care Manage Rev 35(3):246. https:// doi.org/10.1097/HMR.0b013e3181dc826d

Lake ET et al (2002) Development of the practice environment scale of the nursing work index. Res Nurs Health 25(3):176. https://doi.org/ 10.1002/nur.10032

Lee SY, Kim CW, Kang JH, Yoon TH, Kim CS (2014) Influence of the nursing practice environment on job satisfaction and turnover intention.J Prev Med Public Health 47(5):258-265. https://doi.org/ 10.3961/jpmph.14.002

Li J-Y, You Z, Wang Q, Zhou Z-J, Qiu Y, Luo R et al (2020) The epidemic of 2019-novel-coronavirus (2019-nCoV) pneumonia and insights for emerging infectious diseases in the future. Microbes Infect 22(2):80-85. https://doi.org/10.1016/j.micinf.2020.02.002 
Liu K, You L-M, Chen S-X et al (2012) The relationship between hospital work environment and nurse outcomes in Guangdong, China: a nurse questionnaire survey. J Clin Nurs 21(9-10):1476-1485. https://doi.org/10.1111/j.1365-2702.2011.03991.x

Munyewende P, Rispel L, Chirwa T et al (2014) Positive practice environments influence job satisfaction of primary health care clinic nursing managers in two south african provinces. Hum Resour Health 12(1):27. https://doi.org/10.1186/1478-4491-12-27

Rivaz M, Momennasab M, Yektatalab S, Ebadi A et al (2017) Adequate resources as essential component in the nursing practice environment: a qualitative study. J Clin Diagn Res 11(6):IC01-IC04. https://doi.org/10.7860/JCDR/2017/25349.9986

Stalpers D, De Brouwer BJM, Kaljouw MJ, Schuurmans MJ et al (2015) Associations between characteristics of the nurse work environment and five nurse-sensitive patient outcomes in hospitals: a systematic review of literature. Int J Nurs Stud 52(4):817-835. https://doi.org/ 10.1016/j.jinurstu.2015.01.005

Wang L, Li LZ (2011) Reliability and validity of Chinese version of the practice environment scale (in Chinese). Chin J Nurs 46(2):121
Wang Y, Dong W, Mauk K et al (2015) Nurses' practice environment and their job satisfaction: a study on nurses caring for older adults in Shanghai. PLoS One 10(9):e0138035. https://doi.org/10.1371/ journal.pone. 0138035

Yang Q, Ju M, Li YX et al (2017) Preliminary study on the construction of intelligent nursing in the context of "Internet +" (in Chinese). J Nurs 32(11):8-10

Yao J, Liu Y, Cheng J (2020) Standardize the management procedures for breast cancer patients during the outbreak of Covid-19 in Wuhan, China. Breast Cancer Res Treat183(1):213-216. https://doi.org/10. 1007/s10549-020-05743-X

Ying X, Hai Y, Wen H et al (2016) Analysis of the assessment results of nursing practice environment in 5 large hospitals (in Chinese). Chin Nurs Manag 16(7):873-878. https://doi.org/10.1097/NNA. 0b013e3182714506

Publisher's note Springer Nature remains neutral with regard to jurisdictional claims in published maps and institutional affiliations. 